\title{
HIV-Associated Nephropathy in Africa: Pathology, Clinical Presentation and Strategy for Prevention
}

\author{
Nazik Elmalaika Husain ${ }^{\mathrm{a}}$, Mohamed H. Ahmed ${ }^{\mathrm{b}, \mathrm{h}}$, Ahmed O. Almobarak ${ }^{\mathrm{c}}$, Sufian K. Noor ${ }^{\mathrm{d}}$, \\ Wadie M. Elmadhoun ${ }^{e}$, Heitham Awadalla ${ }^{\mathrm{f}}$, Clare L. Woodward ${ }^{\mathrm{g}}$, \\ Dushyant Mitalg
}

\begin{abstract}
The human immunodeficiency virus (HIV) infection can lead to progressive decline in renal function known as HIV-associated nephropathy (HIVAN). Importantly, individuals of African ancestry are more at risk of developing HIVAN than their European descent counterparts. An in-depth search on Google Scholar, Medline and PubMed was conducted using the terms "HIVAN" and "pathology and clinical presentation", in addition to "prevalence and risk factors for HIVAN", with special emphasis on African countries for any articles published between 1990 and 2017. HIVAN is characterized by progressive acute renal failure, proteinuria and enlarged kidneys. A renal biopsy is necessary to establish definitive diagnosis. Risk factors are male gender, low CD4 counts, high viral load and long use of combined antiretroviral medication (cART). There is a wide geographical variation in the prevalence of HIVAN as it ranges from $4.7 \%$ to $38 \%$ worldwide and little published literature is available about its prevalence in African nations. Microalbuminuria is a common finding in African populations and is significantly associated with severity of HIV disease progression and CD4 count less than 350 cells $\mu \mathrm{L}$. Other clinical presentations in African populations include acute kidney injury (AKI), nephrotic syndrome and chronic kidney disease. The
\end{abstract}

Manuscript submitted October 19, 2017, accepted November 6, 2017

${ }^{a}$ Department of Pathology, Faculty of Medicine and Health Sciences, Omdurman Islamic University, Khartoum, Sudan

${ }^{b}$ Department of Medicine and HIV Metabolic Clinic, Milton Keynes University Hospital NHS Foundation Trust, Eaglestone, Milton Keynes, Buckinghamshire, UK

'Department of Pathology, Faculty of Medicine, University of Medical Sciences and Technology, Khartoum, Sudan

${ }^{\mathrm{d} D e p a r t m e n t}$ of Medicine, Faculty of Medicine and Health Sciences, Nile Valley University, Atbara, Sudan

eDepartment of Pathology, Faculty of Medicine and Health Sciences, Nile Valley University, Atbara, Sudan

fDepartment of Community Medicine, Faculty of Medicine, University of Khartoum, Khartoum, Sudan

gDepartment of HIV and Blood Borne Viruses, Milton Keynes University Hospital, NHS Foundation Trust, Milton Keynes, UK

${ }^{\mathrm{h}}$ Corresponding Author: Mohamed H. Ahmed, Department of Medicine and HIV Metabolic Clinic, Milton Keynes University, Hospital NHS Foundation Trust, Eaglestone, Milton Keynes, Buckinghamshire, UK.

Email: elziber@yahoo.com

doi: https://doi.org/10.14740/jocmr3235w main HIV-associated renal pathological lesions were focal segmental glomerulosclerosis, mainly the collapsing form, acute interstitial nephritis (AIN), and immune complex-mediated glomerulonephritis (ICGN). HIV infection-induced transcriptional program in renal tubular epithelial cells as well as genetic factors is incriminated in the pathogenesis of HIVAN. This narrative review discusses the prevalence, presentation, pathogenesis and the management of HIVAN in Africa. In low resource setting countries in Africa, dealing with HIV complications like HIVAN may add more of a burden on the health system (particularly renal units) than HIV medication itself. Therefore, the obvious recommendation is early use of cART in order to decrease risk factors that lead to HIVAN.

Keywords: HIV-associated nephropathy; Africa; Diabetes; Hypertension; Proteinuria

\section{Prevalence of Human Immunodeficiency Virus (HIV) Nephropathy in Africa}

There is a wide geographical variation in the prevalence of HIV-associated nephropathy (HIVAN); it ranges from 38\% to $48.5 \%$ worldwide [1-4]. However, one of the limitations of this review is that this area is not well researched in Africa and as a result few publications are available about prevalence in African countries $[1,5]$. The long use of combined antiretroviral medication (cART) has led to higher incidence of HIVAN in the recent years though a plateau was reached at its start. Middle-aged HIV-positive individuals of African ancestry showed a markedly greater possibility of developing HIVAN than their European descent counterparts [4]. In 2004, Dia reported the first case of HIVAN in Senegal in a 40-year-old black patient with fluid retention with renal edema syndrome and immunosuppressive signs, who was found to be HIV-positive with with low CD4 count and no known causes of nephrotic syndrome [6].

The prevalence of HIVAN in South Africa (have the highest rate of HIV worldwide) was estimated to be around $83 \%$ among $615 \mathrm{HIV}$-infected patients screened for proteinuria in a hospital-based study, $24 \%$ had microalbuminuria and $86 \%$ of the biopsied patients showed HIVAN [5, 7]. Furthermore, the incidence of HIVAN increased from $6.6 \%$ in 2000 to $25.7 \%$ 
in 2009 in Cape Town [8]. The prevalence of HIVAN showed significant variation in different African nations especially in young individuals and those with short duration of HIV infection. For instance, about $6.6 \%$ out of 863 individuals with endstage renal disease (ESRD) diagnosed in a general hospital in Cameroon over a period of 10 years were found to be HIV-positive. Importantly, these patients were noticed to be younger, more commonly to be women, to be single and unemployed [9], whilst high prevalence of HIVAN was noted in Nigeria. The estimated prevalence of HIVAN in one locality in Nigeria was estimated to be $77 \%$ and $76.7 \%$ in the age group of $21-40$ years [10]. Alarmingly, children with HIV are not protected against HIVAN. For example, it was estimated that the prevalence of HIVAN in children in Nigeria was $31.6 \%$ and this can be associated with high mortality. Risk factors in children can be proteinuria, advanced disease, low CD4 count and the use of the highly active antiretroviral therapy (HAART) [1114]. It seems that genetic factors may also play an important role in the development of HIVAN, as different populations in Africa showed very low prevalence of HIVAN. For instance, HIVAN was seen in only $0.8 \%$ of 338 HIV-positive patients of Ethiopian ancestry [15]. Furthermore, no single patient was found to have HIVAN among $176 \mathrm{HIV}$-infected patients in a study that included 126 Ethiopians and 50 non-Ethiopian Israelis. The authors attributed their findings to population-based differences in host genetic factors rather than to differences in HIV infection control or viral subtype [16].

\section{Presentation of HIV Nephropathy in Africa}

Chronic kidney disease (CKD) is an important comorbidity during HIV infection. It is predominantly caused by HIVAN that has largely been detected in people of African origin [17] and HIVAN has a broad spectrum of renal manifestations. HIVAN may present with acute renal failure, proteinuria, microalbuminuria, nephrotic syndrome, chronic renal failure or high kidney echogenicity on ultra-sonographic examination. Adults with clinically non-advanced HIV disease, commonly show less severe renal impairment. Out of 526 Malawian ART-naive patients with WHO stages I or II HIV, nearly fourth $(23.3 \%)$ of them had proteinuria $(\geq 1+)$. More than half $(57.4 \%)$ had reduced creatinine clearance $(\mathrm{CrCl})(<90 \mathrm{~mL} / \mathrm{min}): 18.8 \%$ showed moderate $(\mathrm{CrCl} 30-59 \mathrm{~mL} / \mathrm{min})$ and $2.2 \%$ showed severe $(\mathrm{CrCl}<30 \mathrm{~mL} / \mathrm{min})$ renal dysfunction. Renal biopsy studies confirmed HIVAN in $1.8-21.2 \%$. This highlights the high benefit of assessing renal function as a routine test in HIV patients [18].

Proteinuria is commonly detected in HIV-positive patients in Nigeria. Emem et al encountered renal disease (proteinuria and/or elevated serum creatinine) in $38 \%$ out of 400 consecutive adult HIV/AIDS patients [19]. In a case-control study, Esezobor et al found that compared with $6 \%$ of the 50 controls, $20.5 \%$ of the 88 Nigerian children infected with HIV had proteinuria $(\mathrm{P}=0.026)$ [14]. In another Nigerian case-control study, the mean protein excretion/24 h was significantly greater in 79 AIDS group compared to 57 controls $(2.99 \pm 54 \mathrm{~g}$ and $0.56 \pm 0.12 \mathrm{~g}$, respectively, $\mathrm{P}=0.001)$. Inversely, controls demonstrated high levels of glomerular filtration rate (GFR) when correlated to the study group $(103.30 \pm 37.78$ and 68.03 \pm 37.55 , respectively, $P=0.004)$. Interestingly, subjects in the AIDS group with renal disease had a significantly longer duration of illness when matched to those un-diseased (12.33 \pm 8.67 months and $7.28 \pm 7.78$ months, respectively, $\mathrm{P}=0.008$ ) [20].

Moreover, microalbuminuria was detected in $28.8 \%$ of Tanzanian HIV-infected children at a medical center. Microalbuminuria was considerably connected to the degree of HIV disease progression according to WHO disease stage $(\mathrm{P}=$ $0.0015)$ and a reduced amount of CD4 count, below 350 cells/ $\mu \mathrm{L}(\mathrm{P}=0.044)$. Therefore, to decrease the risk of emerging ESRD, early screening and treatment of microalbuminuria is required, especially for those at high risk (advanced HIV disease and those with a CD 4 count below 350 cells $/ \mu \mathrm{L}$ ). Urinary albumin screening can be done in a situation where routine screening for microalbuminuria is not available [21].

Nonetheless, the nephrotic syndrome represented the most common clinical manifestations of HIVAN in childhood in KwaZulu-Natal, South Africa [22]. Hematological, electrolyte abnormalities and renal impairment were documented in $86.4 \%, 69.4 \%$ and $41 \%$ of patients, respectively on initial presentation [22]. However, ESRD was present in only $4 \%$ of these patients [22]. HIV nephropathy was also reported in $15 \%$ of nephrotic Black African adults in a hospital in Abidjan [23]. At a University Hospital in South West Nigeria, out of 10 kidney disease HIV-infected children, four presented with acute kidney injury (AKI), three with nephrotic syndrome and two with chronic renal failure. One patient had left renal artery stenosis [24]. Moreover, HIVAN was seen in $42.8 \%$ of 294 adult black South Africans with the biopsy-proven cause of nephrotic syndrome in Cape Town in 10 years duration and thought to be accountable for the growing prevalence of ESRD in Africa [25]. Furthermore, proteinuria in the nephrotic range was the predominant clinical indication for a renal biopsy at a single hospital in Cape Town, representing 52.5\% out of 1,284 renal biopsies, followed by acute renal failure (21.3\%), and then asymptomatic urinary abnormalities $(13.6 \%)$. Other indications included chronic renal failure $(6.4 \%)$, acute nephritic syndrome $(5.8 \%)$ and hematuria $(0.3 \%)$ [25]. Nevertheless, non-nephrotic proteinuria was the initial clinical presentation of HIV-associated renal disease in $54 \%$ and nephrotic syndrome in $23 \%$ of African HIV patients. The other clinical manifestations were acute kidney injury and chronic kidney disease in $28 \%$ and $22 \%$, respectively as stated in that study [26].

Using sonographic characterization of 302 HIV/AIDS subjects prospectively for 22 months in Plateau State, Nigeria, $77.7 \%$ of them showed augmented renal echogenicity displaying a high rate of renal disease among them, and $76.7 \%$ of the patients were in the age group 21 - 40 years [10]. Table 1 [10, $14,18-22,25,26]$ provides summary of common presentations of HIVAN. Therefore, regular monitoring of renal function should be part of routine investigation for HIV patients.

\section{Pathological Forms of HIVAN in Africa}

CKD in HIV patients may take place as a consequence of HIV 
Table 1. Different Clinical, Radiological and Biochemical Presentations of HIVAN [10, 14, 18-22, 25, 26]

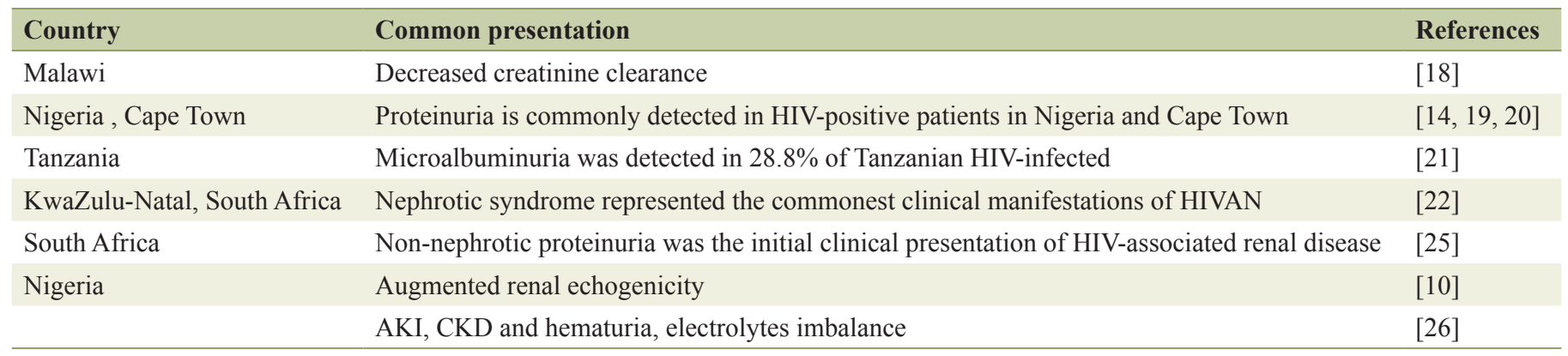

infection, other co-morbid illnesses as well as a result of therapyrelated complications. Regardless of the cause, a variety of renal pathological lesions are seen in renal biopsies obtained from patients with HIV-CKD; commonly HIVAN, the aggressive collapsing form; HIV-immune complex disease; focal segmental glomerulosclerosis (FSGS) and rarely thrombotic microangiopathy $[1,26]$. Membranous nephropathy has also been described [24]. The introduction of antiretroviral therapy (ART) leads to a change in the pattern of CKD with an increasing prevalence of FSGS and decline in the incidence of HIVAN [1].

The main renal pathological lesions of $61 \mathrm{HIV}$ patients were found to be FSGS, mainly the collapsing form HIVAN in $28 \%$, acute interstitial nephritis (AIN) in $26 \%$ and immune complex-mediated glomerulonephritis (ICGN) in $25 \%$ of the cases in Brazil. Baseline CD4 cell count $\geq 200$ cells $/ \mathrm{mm}^{3}$ proved to be a protective factor against CKD (hazard ratio = 0.997; 95\% confidence interval (CI): $0.994-0.999 ; \mathrm{P}=0.012$ ) after 24 months follow-up [27].

Similarly, FSGS was the most common histopathological finding which was seen in 32 (65.3\%) HIV-infected South African children; $13(26.5 \%)$ had collapsing glomerulopathy and $19(38.8 \%)$ had classic FSGS [22].

Acute kidney injury seems to have mostly acute tubular necrosis owing to sepsis, dehydration, and nephrotoxic drugs [5]. Chronic granulomatous tubulo-interstitial nephritis has also been reported in a patient infected with HIV type- 1 and receiving ritonavir-boosted atazanavir [28]. Acute kidney injury in HIV-positive patients, mainly as a consequence of acute tubular necrosis, is thought to arise from a combination of hemodynamic, immunological, and toxic insult [29].

In Uganda, eosinophilic endocapillary proliferative glomerulonephritis (GN) was found to be the most frequent histological finding. It was reported in 27/41 cases [30].

Biopsy findings of seven patients with persistent microalbuminuria in a South African single center showed HIVAN in $86 \%$, membranoproliferative nephropathy in two $(7 \%)$ and interstitial nephritis in three $(10 \%)$, while membranous nephropathy was seen in four patients with HIVAN [7].

In a retrospective study of 99 biopsies for HIV-positive patients in South Africa, the leading histologic types were "classic HIVAN" (27\%) and HIV immune complex kidney disease (HIVICK) (21\%). Other glomerulonephritides encompassed membranous, post-infectious disease, mesangial hyperplasia, and immunoglobulin A nephropathy. While in the HIV-negative group collapsing FSGS and non-specific immune complex disease were not seen, but increased cases of minimal change and membranoproliferative disease [31].

\section{Pathogenesis of HIVAN}

HIVAN is mediated by factors related to the virus, host genetic predisposition and environmental factors. The mechanisms responsible for HIVAN include HIV infection of podocytes and tubular epithelial cells, the molecules accountable for HIV entry, and diverse mechanisms of cell injury [26]. Disease phenotype may be influenced by host response to HIV infection through activation of cytokine pathways [1].

Viral replication and interstitial inflammation play central roles in the pathogenesis of HIVAN. To understand how HIV replication initiates HIVAN, Chen et al in 2016 determined the cellular response of renal tubule epithelial cells (RTECs) to HIV by inspecting the transcriptional profiles of primary RTECs when exposed to T cells, some infected and others not infected with HIV. An innate response to HIV, which further was sub-classified by gene ontology biological process terms, was noticed when HIV-induced gene expression in hRTECs was examined in vitro by Illumina RNA deep sequencing. Their results showed that as compared with cell-free virus infection, exposure to HIV-infected T cells elicited a stronger upregulation of genes responsible for inflammation and immune response, largely the chemokine/cytokine families. They include inflammatory cytokines CCL20, IL6 and IL8-related chemokines: IL8, CXCL1, CXCL2, CXCL3, CXCL5 and CXCL6. They concluded that interactions between primary RTECs and HIV-infected T cells result in the potent induction of inflammatory response genes and release of cytokines/ chemokines from RTECs that can invite extra T cells. Triggering of these genes means an innate response to HIV by nonimmune cells [32].

Recently, pyroptosis, a new type of programed cell death, was thought to be induced by HIV in T lymphocytes through the generation of Nod-like receptor protein 3 (NLRP3) inflammasome complexes. Hague et al (2016) assessed the role of HIV in podocyte NLRP3 inflammasome formation both in vivo and in vitro. Their results revealed that renal cortical slices of HIVtransgenic mice (Tg26) demonstrated amplified expression of NLRP3, ASC (a CARD protein), caspase-1, and IL-1beta proteins, approving the formation of NLRP3 inflammasome complex in podocytes of Tg26 mice. Boosted mRNA levels 
and protein expressions of inflammasome markers (NLRP3, ASC, and caspase-1, and IL-1beta) were also demonstrated in renal tissues of Tg26 mice. Serum of Tg26 mice also showed elevated concentrations of IL-1beta cytokine compared with FVBN mice. Pyroptosis was induced within podocytes by HIV in a dose- and time-dependent way, representing a phenotype of inflammasome activation. They found that caspase-1 inhibitor not only reduced podocyte expression of caspase- 1 and IL1 beta but further provided protection against pyroptosis. This suggests that HIV-induced podocyte injury was facilitated by caspase-1 activation. Interestingly, they instituted that podocyte pyroptosis induced by HIV could be partially inhibited by Tempol (a superoxide dismutase-mimetic agent) and by glyburide (an inhibitor of potassium efflux). Therefore, generation of reactive oxygen species and potassium efflux play a role in HIV-induced pyroptosis and activation of the NLRP3 inflammasome in podocytes [33].

Experimental studies mapped a major HIVAN susceptibility locus (HIVAN1) to chromosome 3A1-A3 in a cross between HIV-1 transgenic mice on the FVB/NJ background (TgFVB) which is a documented model of HIVAN and CAST/ EiJ (CAST) strains, and introgression of a $51.9 \mathrm{Mb}$ segment covering HIVAN1 from CAST into TgFVB caused enhanced progress of nephropathy. So, dormant molecular disorders may lead to nephropathy when exposed to HIV-1 [34].

It has been suggested that genetic factors play a crucial role in the pathogenesis of HIVAN [4, 35]. Purswani et al reported a 3.5 -fold higher odds of CKD in patients carrying high-risk APOL1 genotypes in a nested case-control study of 451 PHIV contributors in the Pediatric HIV/AIDS Cohort Study. They also reported a unadjusted incidence of $1.2 \mathrm{CKD}$ cases/100 person-years (95\% CI: 0.5 - 2.5) in PHIV youth carrying APOL1 high-risk variants, with imperative connotations for sub-Saharan Africa [36]. The alleles that were more implicated as risk factors for CKD in individuals of African descent are APOL1 G1 and G2 rather than the previously examined MYH9 E1 risk haplotype.

About half of African Americans with two APOL1 risk alleles, if untreated, would develop HIVAN. However, it has been perceived that these two variants are not enough to cause disease. The predominant faith is that modifying factors or second hits (including genetic hits) lie beneath the pathogenesis of kidney disease [35].

In 120 patients with HIVAN and CKD and 108 controls from a South-African black population, Kasembeli et al found that $79 \%$ of patients with HIVAN and $2 \%$ of the controls carried two risk alleles (APOL1 G1 and G2 variants). Their study exposed that individuals possessing any combination of two APOL1 risk alleles had 89-fold increased odds (95\% CI: 18 - 912; $\mathrm{P}<0.001$ ) of developing HIVAN when related to HIVpositive controls [37].

Although the two risk alleles were significantly connected to higher odds of HIVAN, APOL1 genotype did not predict confidently this specific histopathology and cannot eliminate the important role of kidney biopsy in the clinical care of HIVpositive blacks who are with proteinuria more than $3.5 \mathrm{mg} / 24$ $\mathrm{h}$ urine or unexplained kidney disease [38]. The findings of Da Silva et al in 2016 also strengthen the importance of renal biopsy in HIV patients with kidney impairment and/or pro- teinuria [27].

Nevertheless, the rates of the APOL1 G1 and G2 variants among Ethiopians are significantly and dramatically lower than those observed among HIV-infected African-Americans, African-Americans and West Africans explaining the lack of HIVAN among HIV patients of Ethiopian ancestry [15]. On the other hand, even though birth in a sub-Saharan African (SSA) country was ominously related to baseline CKD, Schoffelen et al reported that it had no influence on newly evolving CKD upon a time. In their large Dutch AIDS Therapy Evaluation in the Netherlands (ATHENA) cohort, authors found that patients of SSA origin and those born in Western Europe, Australia, or New Zealand had a similar risk of newly emerging CKD (adjusted hazard ratio, 1.00; 95\% CI: $0.63-1.59$ ). However, they followed the patients for a median duration of only 4.7 years [17].

Booth et al described the renal pathology of HIV-associated immune complex kidney (HIVICK) disease and compared the clinical characteristics of patients with HIVICK (65 patients) with those with IgA nephropathy (27 patients) and HIVAN (70 patients) in a multicenter study. Their results revealed that black ethnic background and HIV RNA were related to HIVICK, use of ART with IgA nephropathy and black ethnicity and CD4 cell count with HIVAN. It also showed that HIVICK was linked to lower rates of end-stage kidney disease progression in comparison with HIVAN and IgA nephropathy $(\mathrm{P}<0.0001)$. They suggested a pathogenic role for HIV replication in the development of HIVICK and that ART may recover kidney function in patients who have noticeable HIV RNA at the time of HIVICK diagnosis [39].

The epidemiology of HIV-related CKD has been changed with the advent of cART in the mid-1990s. With the era of prevalent use of cART and the aging of HIV population, a change has been observed in the scales of HIV-related CKD. HIVAN is becoming rare in patients under medical care, and the problem of comorbid disease is growing [5, 40].

Surprisingly, HIV-1 particles were detected into continuous ambulatory peritoneal dialysis effluents of HIV-positive patients with ESRD on HAART in South Africa even in patients with suppressed plasma viral load without equivalent recognition in the paired plasma [41]. This may justify the presence of ongoing emerging kidney disease in spite of the use of HAART; however, these findings need to be taken seriously with the further assessment.

\section{Risk Factors of HIVAN in Africa}

The severity of the HIV infection (based on $\mathrm{CD}^{+}$count), anemia, malnutrition and increasing age were suggested as possible risk factors for renal disease [19]. Anemia and malnutrition are widely encountered in an African population. The combination of HIV infection and poorly controlled diabetes mellitus (DM) which is common in Africa exacerbates the complications and leads frequency to nephropathy. Pillay et al reported substantial variations in the incidence of nephropathy when reviewed HIV-infected and uninfected diabetic patients with evident proteinuria (25.66\% vs. $15.43 \%$ ) [42]. 


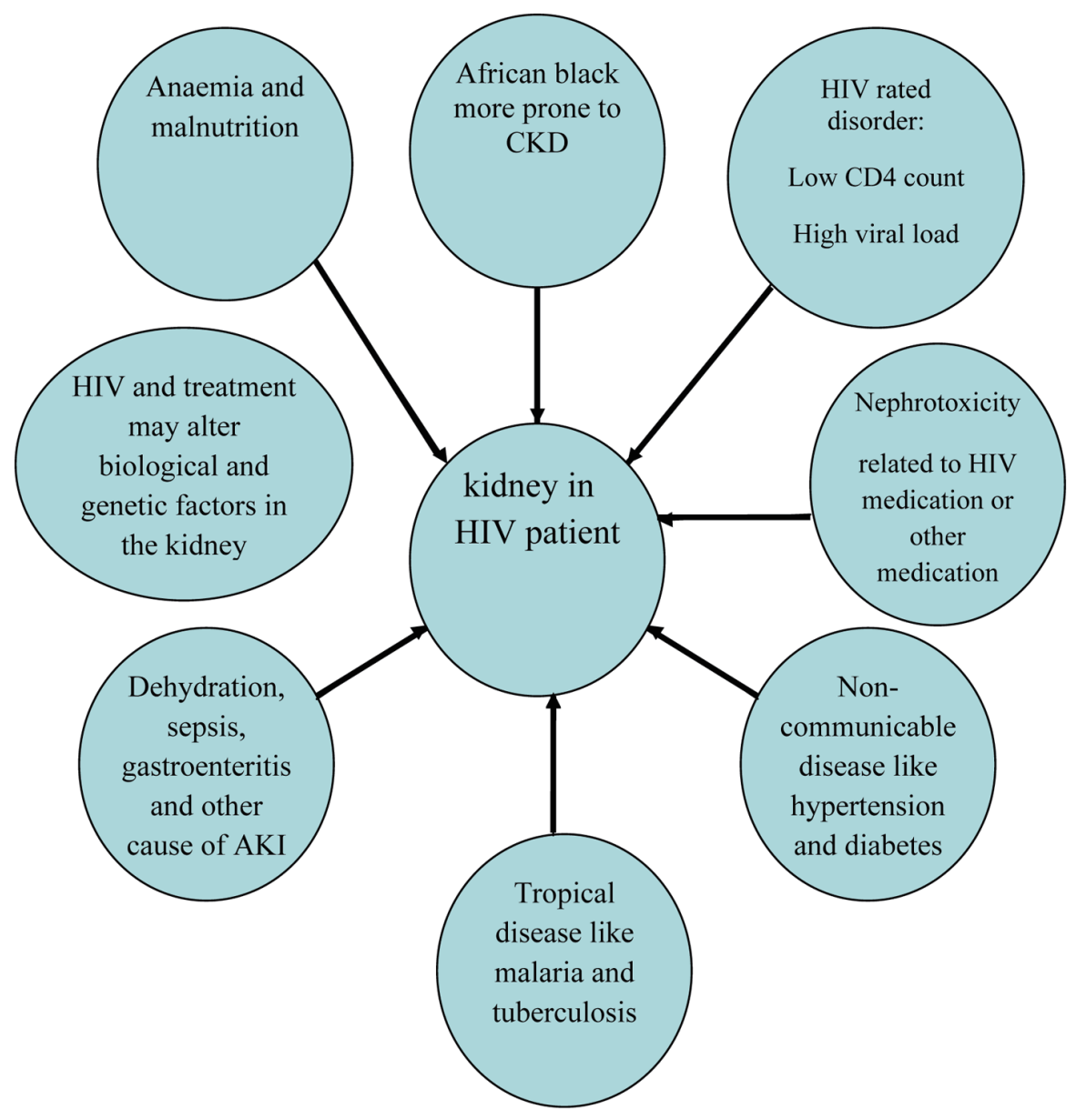

Figure 1. Some of the risk factors that may lead to HIVAN in Africa.

Furthermore, the unusual pattern of CKD of the black race was partly attributed to renal lesions related to tropical diseases and they were suggested to play a significant role in the increased frequency of the CKD in sub-Saharan Africa [43]. In addition to epidemics of HIV, tuberculosis, and non-communicable disease, predominantly hypertension and diabetes have implications on the development of both CKD and acute kidney injury. This increased frequency of HIVAN in SSA may be justified by the late presentation and lack of effective screening for renal disease in HIV-positive patients. Furthermore, the definitive diagnosis necessitates a renal biopsy, which is often not possible in many regions of sub-Saharan Africa [44].

In a recent study, a small but significant decline in kidney function has been detected in patients on tenofovir with baseline estimated glomerular filtration rate $(\mathrm{eGFR}) \geq 90 \mathrm{~mL} /$ $\mathrm{min} / 1.73 \mathrm{~m}^{2}$ [45]. In the same study, CD4 count $<200$ cells $/ \mu \mathrm{L}$ was shown to be significantly linked to low eGFR [45].

Govender et al determined the independent clinical risk factors for in-hospital mortality (IHM) for 690 older (aged $\geq 50$ years old) HIV-infected adults from a hospital administrative database using logistic regression. Male gender $(\mathrm{P}$ $=0.005), \mathrm{CD} 4$ count $<350$ cells $/ \mathrm{mm}^{3}(\mathrm{P}=0.035)$, unknown CD4 count $(\mathrm{P}=0.048)$, tuberculosis $(\mathrm{P}=0.033)$ and renal failure $(\mathrm{P}=0.013)$ were considered potential risk factors for IHM
[46]. Focused assessment with sonography for HIV-associated TB was considered one of the most relevant point-of-care ultrasound applications in SSA settings [47]. Management of HIVAN and other non-comunicable diseases in Africa and in low-income and middle-income countries, in general, necessitates combined clinicopathological clinics that will enable early screening, diagnosis and monitoring [48].

\section{Strategy for Prevention and Management of HIVAN in Africa}

Prevention and management of HIVAN is summarized in Figures 1 and 2. The benefit of screening for HIVAN should be part of the routine follow tests for individuals with HIV on basis of 4 - 6 months. This should include urine for albuminuria, proteinuria and plasma test for creatinine and eGFR. Presence of proteinuria and decline in renal function should prompt treating HIV physicians to refer the patient to nephrologists according to guidelines in place. The management of risk factors that lead to HIVAN cannot be over-emphasized (Figs. 1 and 2). Therefore, researchers in the future may be able to address the following interesting points about HIVAN 


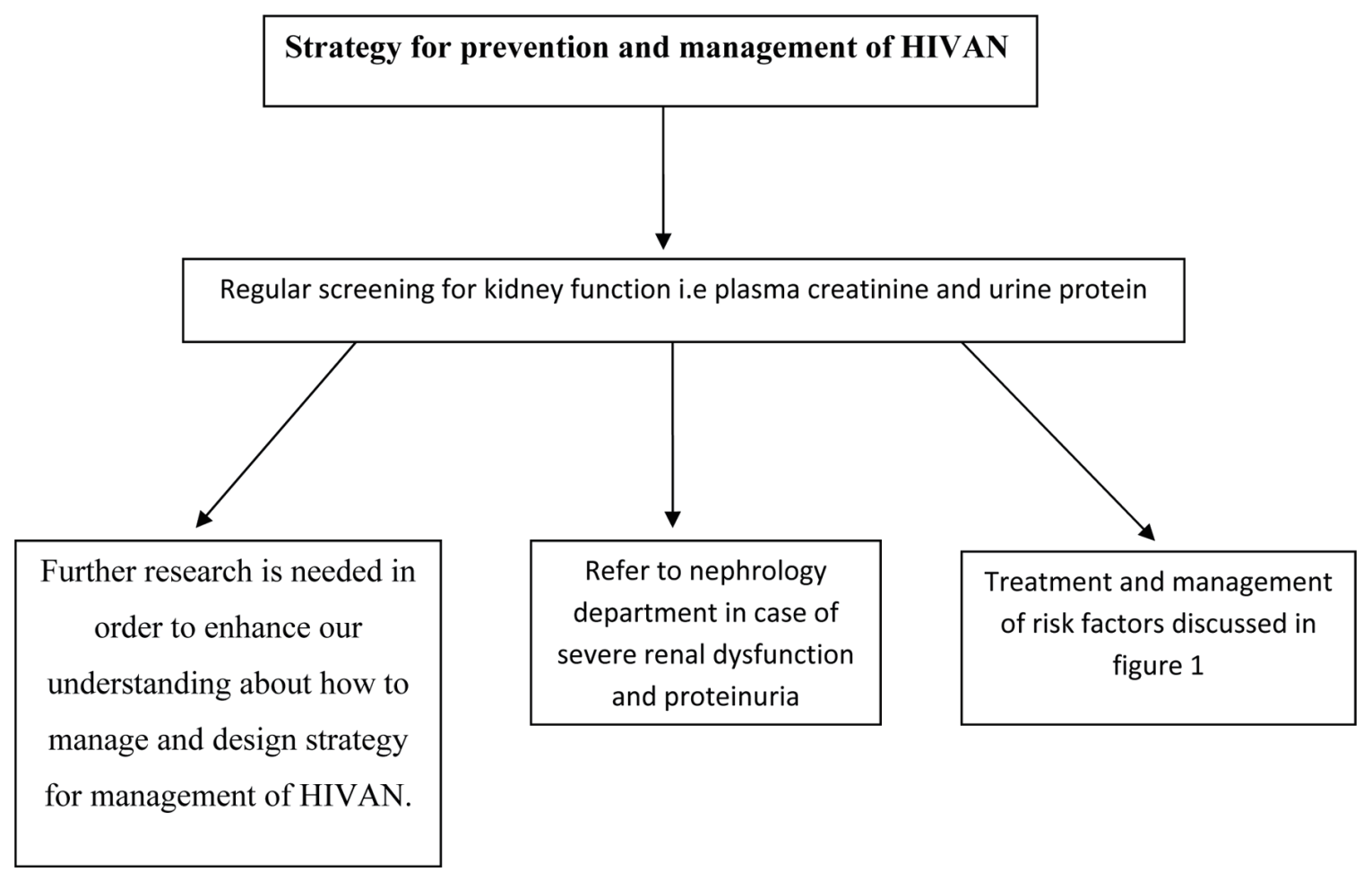

Figure 2. Possible valid strategies in management and prevention of HIVAN in Africa.

in Africa: 1) Prevalence and risk factors of HIVAN in other African countries. 2) Role of ethnicity in HIVAN. 3) Why the incidence of HIVAN is low in Ethopia and high in Nigeria and South Africa. 4) What is incidence and risk factors of HIVAN of African population living in Western countries. 5) Multicenter research studies will yield significant observations and help in increasing our understanding of pathognesis, management and prevention of HIVAN in African populations.

\section{Conclusion}

HIVAN prevalence in Africa is high. The first and common manifestation of this syndrome is proteinuria. Definite diagnosis is achieved by renal biopsy. Several risk factors were identified including diabetes, hypertension, low CD4 count, high viral load, anemia, infectious disease and malnutrition. Routine screening is important to treat and manage those at risk and risk factors like diabetes and hypertension at an early phase of the disease. Therefore, Ahmed et al suggested that metabolic clinic should be integral part of HIV services; further information about HIV metabolic clinic in Milton Keynes University Hospital, UK can be obtained from reference [49]. Further research is needed in order to enhance our understanding about how to manage and design strategy for management of HIVAN (Fig. 2).

\section{Competing Interests}

The authors declare that they have no competing interests.

\section{Abbreviations}

HIVAN: HIV-associated nephropathy; WHO: World Health Organization

\section{References}

1. Naicker S, Rahmanian S, Kopp JB. HIV and chronic kidney disease. Clin Nephrol. 2015;83(7 Suppl 1):32-38.

2. Vigneau C, Guiard-Schmid JB, Tourret J, Flahault A, Rozenbaum W, Pialoux G, Rondeau E. The clinical characteristics of HIV-infected patients receiving dialysis in France between 1997 and 2002. Kidney Int. 2005;67(4):1509-1514.

3. Poignet JL, Desassis JF, Chanton N, Litchinko MB, Zins B, Kolko A, Patte R, et al. [Prevalence of HIV infection in dialysis patients: results of a national multicenter study]. Nephrologie. 1999;20(3):159-163.

4. Diana NE, Naicker S. Update on current management of chronic kidney disease in patients with HIV infection. Int J Nephrol Renovasc Dis. 2016;9:223-234.

5. Swanepoel CR, Wearne N, Duffield MS, Okpechi IG. The evolution of our knowledge of HIV-associated kidney disease in Africa. Am J Kidney Dis. 2012;60(4):668-678.

6. Dia D, Fall K, Niang A, Guibal A, Fall S, Dieng M, Diallo I, et al. [HIV associated nephropathy syndrome: a case report in Dakar]. Dakar Med. 2004;49(1):61-63.

7. Han TM, Naicker S, Ramdial PK, Assounga AG. A crosssectional study of HIV-seropositive patients with vary- 
ing degrees of proteinuria in South Africa. Kidney Int. 2006;69(12):2243-2250.

8. Okpechi I, Swanepoel C, Duffield M, Mahala B, Wearne N, Alagbe S, Barday Z, et al. Patterns of renal disease in Cape Town South Africa: a 10-year review of a singlecentre renal biopsy database. Nephrol Dial Transplant. 2011;26(6):1853-1861.

9. Halle MP, Takongue C, Kengne AP, Kaze FF, Ngu KB. Epidemiological profile of patients with end stage renal disease in a referral hospital in Cameroon. BMC Nephrol. 2015;16:59.

10. Ulu UO, Agbaji O, Agwu KK. Sonographic characterization of renal pathologies in HIV/AIDS in Plateau State, Nigeria. Niger J Med. 2012;21(2):160-164.

11. Anochie IC, Eke FU, Okpere AN. Human immunodeficiency virus-associated nephropathy (HIVAN) in Nigerian children. Pediatr Nephrol. 2008;23(1):117-122.

12. Ikpeme EE, Ekrikpo UE, Akpan MU, Ekaidem SI. Determining the prevalence of human immunodeficiency virus-associated nephropathy (HIVAN) using proteinuria and ultrasound findings in a Nigerian paediatric HIV population. Pan Afr Med J. 2012;11:13.

13. Eke FU, Anochie IC, Okpere AN, Eneh AU, Ugwu RO, Ejilemele AA, Ugboma HU. Microalbuminuria in children with human immunodeficiency virus (HIV) infection in Port Harcourt, Nigeria. Niger J Med. 2010;19(3):298301.

14. Esezobor CI, Iroha E, Onifade E, Akinsulie AO, Temiye EO, Ezeaka C. Prevalence of proteinuria among HIVinfected children attending a tertiary hospital in Lagos, Nigeria. J Trop Pediatr. 2010;56(3):187-190.

15. Behar DM, Kedem E, Rosset S, Haileselassie Y, Tzur S, Kra-Oz Z, Wasser WG, et al. Absence of APOL1 risk variants protects against $\mathrm{HIV}$-associated nephropathy in the Ethiopian population. Am J Nephrol. 2011;34(5):452459.

16. Behar DM, Shlush LI, Maor C, Lorber M, Skorecki K. Absence of HIV-associated nephropathy in Ethiopians. Am J Kidney Dis. 2006;47(1):88-94.

17. Schoffelen AF, Smit C, van Lelyveld SF, Vogt L, Bauer MP, Reiss P, Hoepelman AI, et al. Diminished impact of ethnicity as a risk factor for chronic kidney disease in the current HIV treatment era. J Infect Dis. 2015;212(2):264274.

18. Struik GM, den Exter RA, Munthali C, Chipeta D, van Oosterhout JJ, Nouwen JL, Allain TJ. The prevalence of renal impairment among adults with early HIV disease in Blantyre, Malawi. Int J STD AIDS. 2011;22(8):457-462.

19. Emem CP, Arogundade F, Sanusi A, Adelusola K, Wokoma F, Akinsola A. Renal disease in HIV-seropositive patients in Nigeria: an assessment of prevalence, clinical features and risk factors. Nephrol Dial Transplant. 2008;23(2):741-746.

20. Agaba EI, Agaba PA, Sirisena ND, Anteyi EA, Idoko JA. Renal disease in the acquired immunodeficiency syndrome in north central Nigeria. Niger J Med. 2003;12(3):120-125.

21. Mosten IK, Hamel BC, Kinabo GD. Prevalence of persistent microalbuminuria and associated factors among HIV infected children attending a Tertiary Hospital in Northern Tanzania: a cross sectional, analytical study. Pan Afr Med J. 2015;20:251.

22. Ramsuran D, Bhimma R, Ramdial PK, Naicker E, Adhikari M, Deonarain J, Sing Y, et al. The spectrum of HIV-related nephropathy in children. Pediatr Nephrol. 2012;27(5):821-827.

23. Diallo AD, Nochy D, Niamkey E, Yao Beda B. [Etiologic aspects of nephrotic syndrome in Black African adults in a hospital setting in Abidjan]. Bull Soc Pathol Exot. 1997;90(5):342-345.

24. Ademola AD, Asinobi OO, Oladokun RE, Ogunkunle OO, Okoloz CA, Ogbole GE. Kidney disease in hospitalised HIV positive children in Ibadan, south west Nigeria. Afr J Med Med Sci. 2012;41(2):221-230.

25. Okpechi IG, Rayner BL, Swanepoel CR. Nephrotic syndrome in adult black South Africans: HIV-associated nephropathy as the main culprit. J Natl Med Assoc. 2010;102(12):1193-1197.

26. Rosenberg AZ, Naicker S, Winkler CA, Kopp JB. HIV-associated nephropathies: epidemiology, pathology, mechanisms and treatment. Nat Rev Nephrol. 2015;11(3):150160 .

27. da Silva DR, Gluz IC, Kurz J, Thome GG, Zancan R, Bringhenti RN, Schaefer PG, et al. Multiple facets of HIV-associated renal disease. Braz J Med Biol Res. 2016;49(4):e5176.

28. Viglietti D, Verine J, De Castro N, Scemla A, Daudon M, Glotz D, Pillebout E. Chronic interstitial nephritis in an HIV type-1-infected patient receiving ritonavir-boosted atazanavir. Antivir Ther. 2011;16(1):119-121.

29. Arendse CG, Wearne N, Okpechi IG, Swanepoel CR. The acute, the chronic and the news of HIV-related renal disease in Africa. Kidney Int. 2010;78(3):239-245.

30. Walker A, Ellis J, Irama M, Senkungu J, Nansera D, Axton J, Coward RJ, et al. Eosinophilic glomerulonephritis in children in Southwestern Uganda. Kidney Int. 2007;71(6):569-573.

31. Gerntholtz TE, Goetsch SJ, Katz I. HIV-related nephropathy: a South African perspective. Kidney Int. 2006;69(10):1885-1891.

32. Chen P, Yi Z, Zhang W, Klotman ME, Chen BK. HIV infection-induced transcriptional program in renal tubular epithelial cells activates a CXCR2-driven CD4+ T-cell chemotactic response. AIDS. 2016;30(12):1877-1888.

33. Haque S, Lan X, Wen H, Lederman R, Chawla A, Attia $\mathrm{M}$, Bongu RP, et al. HIV Promotes NLRP3 Inflammasome Complex Activation in Murine HIV-Associated Nephropathy. Am J Pathol. 2016;186(2):347-358.

34. Papeta N, Patel A, D'Agati VD, Gharavi AG. Refinement of the HIVAN1 Susceptibility Locus on Chr. 3A1A3 via Generation of Sub-Congenic Strains. PLoS One. 2016;11(10):e0163860.

35. Kasembeli AN, Duarte R, Ramsay M, Naicker S. African origins and chronic kidney disease susceptibility in the human immunodeficiency virus era. World J Nephrol. 2015;4(2):295-306.

36. Purswani MU, Patel K, Winkler CA, Spector SA, Hazra R, Seage GR, 3rd, Mofenson L, et al. Brief report: APOL1 
renal risk variants are associated with chronic kidney disease in children and youth with perinatal HIV infection. J Acquir Immune Defic Syndr. 2016;73(1):63-68.

37. Kasembeli AN, Duarte R, Ramsay M, Mosiane P, Dickens C, Dix-Peek T, Limou S, et al. APOL1 risk variants are strongly associated with HIV-associated nephropathy in black South Africans. J Am Soc Nephrol. 2015;26(11):2882-2890.

38. Atta MG, Estrella MM, Skorecki KL, Kopp JB, Winkler CA, Wasser WG, Shemer R, et al. Association of APOL1 genotype with renal histology among black hiv-positive patients undergoing kidney biopsy. Clin J Am Soc Nephrol. 2016;11(2):262-270.

39. Booth JW, Hamzah L, Jose S, Horsfield C, O’Donnell P, McAdoo S, Kumar EA, et al. Clinical characteristics and outcomes of HIV-associated immune complex kidney disease. Nephrol Dial Transplant. 2016;31(12):20992107.

40. Mallipattu SK, Salem F, Wyatt CM. The changing epidemiology of HIV-related chronic kidney disease in the era of antiretroviral therapy. Kidney Int. 2014;86(2):259-265.

41. Ndlovu KC, Sibanda W, Assounga A. Detection of human immunodeficiency virus-1 ribonucleic acid in the peritoneal effluent of renal failure patients on highly active antiretroviral therapy. Nephrol Dial Transplant. 2017;32(4):714-721.

42. Pillay S, Aldous C, Mahomed F. A deadly combination - HIV and diabetes mellitus: Where are we now? S Afr
Med J. 2016;106(4):54.

43. Pakasa NM, Sumaili EK. [Pathological peculiarities of chronic kidney disease in patient from sub-Saharan Africa. Review of data from the Democratic Republic of the Congo]. Ann Pathol. 2012;32(1):40-52.

44. Wearne N, Okpechi IG. HIV-associated renal disease - an overview. Clin Nephrol. 2016;86(13):41-47.

45. De Waal R, Cohen K, Fox MP, Stinson K, Maartens G, Boulle A, Igumbor EU, et al. Changes in estimated glomerular filtration rate over time in South African HIV1-infected patients receiving tenofovir: a retrospective cohort study. J Int AIDS Soc. 2017;20(1):21317.

46. Govender K, Suleman F, Moodley Y. Clinical risk factors for in-hospital mortality in older adults with HIV infection: findings from a South African hospital administrative dataset. Pan Afr Med J. 2017;26:126.

47. Heller T, Mtemang'ombe EA, Huson MA, Heuvelings CC, Belard S, Janssen S, Phiri S, et al. Ultrasound for patients in a high HIV/tuberculosis prevalence setting: a needs assessment and review of focused applications for Sub-Saharan Africa. Int J Infect Dis. 2017;56:229-236.

48. Mayne ES, George JA. Mortal allies: human immunodeficiency virus and noncommunicable diseases. Curr Opin HIV AIDS. 2017;12(2):148-156.

49. Ahmed MH, Woodward C, Mital D. Metabolic clinic for individuals with HIV/AIDS: a commitment and vision to the future of HIV services. Cardiovasc Endocrinol. 2017;6(3):109-112. 